\title{
Survey of Medication Error Factors from Nurses' Perspective
}

\author{
Zahra Pournamdar ${ }^{1}$ and Sadegh Zare ${ }^{2 *}$
}

${ }^{1}$ Community Nursing Research Center, Pregnancy Health Research Center, Zahedan University of Medical Sciences, Zahedan, Iran

${ }^{2}$ Student Scientific Research Center, Zahedan University of Medical Sciences, Zahedan, Iran

*Corresponding author: Zare S, Student Scientific Research Center, Zahedan University of Medical Sciences, Zahedan, Iran; E-mail: zaresadegh93@yahoo.com

Received: Apr 18, 2016; Accepted: Jun 19, 2016; Published: Jun 26, 2016

Copyright: (c) 2016 Pournamdar Z et al. This is an open-access article distributed under the terms of the Creative Commons Attribution License, which permits unrestricted use, distribution, and reproduction in any medium, provided the original author and source are credited.

\begin{abstract}
The nurses are the health-care service providers of the hospitals' front lines, and they play a particular role in offering service to the patients and managing medication activities and interacting with other clinical staff. Therefore, the survey and discovery of the main reasons behind medication errors from their perspective can be effective on the error identification and teaching the appropriate strategies for preventing the errors. Therefore, the presents study aims at the survey of the nurses' perspectives regarding the medication error reasons. The present study is a descriptive research which has been conducted on 119 nurses in 2016. After the questionnaires were gathered, data were analyzed by the use of SPSS 19 and descriptive statistics. The study population's average age was $28.86 \pm 6.45 ; 101$ individuals were women, and 87 people had passed courses on ethics. The highest mean score was obtained in the factors related to hospital sections and departments. Also, the highest mean score regarding the questionnaire items was obtained for the items "the low nurse to patient ratio in departments and hospital sections" and "the high volume of the works," and the lowest mean score was obtained for the item "despondency and disinterest regarding the nursing occupation." The nursing staff should be enhanced in their awareness of types and reasons of medication errors and the way they should be reported in treatment and health centers and particularly training hospitals associated with Zahedan University of Medical Sciences.
\end{abstract}

Keywords: Medication error; Medication error reasons; Nurses; Zahedan

\section{Introduction}

The rapid changes in treatment and health systems have posed numerous ethical issues to medical professional staff $[1,2]$. Nowadays, the issue of complaining and suing and patients' dissatisfaction of the physicians and nurses and the other treatment and health service providers due to reasons, such as violations and diagnosis, treatment mistakes, are increasingly growing [3]. Nowadays, more than twenty thousand drugs are consumed around the world, the inappropriate use of which can expose the patients to severe risks and dangers [4]. The correct method of drug administration, which is the fundamental responsibility of a nurse, seems vital for patients' safety. The role played by nurses in the process of administering drugs—-giving the right drug to the right patient at the right time at a suitable dosage through the execution of a convenient method, evaluating and supporting the favorable effects; counteracting measures in case of the emergence of unfavorable effects; and correct recording, teaching, and training concerning how the drugs should be administered to the patients-is highly critical.

Nurses have a very significant responsibility in preventing medication errors from happening since they play the main role in drug administration [5]. Generally speaking, medication errors occur as a result of clinical and medical personnel falling short of performing their duties correctly [6]. On average, nurses spend $40 \%$ of their time on drug administration [7]. Medication errors can create serious problems in the nurses' normal work process and expose the patients to risks that can be prevented [8]. Medication errors result in an increase in the duration of hospital stays and increase in the costs as well, and they can cause a sense of distrust among the patients which is usually followed by patients' dissatisfaction of the systems offering health care, and they can also cause nurses to develop stress and be faced with ethical conflicts $[9,10]$.
Medication errors comprise a substantial part of different types of errors and mistakes taking place in the hospitals, and these include omissions, giving the wrong drug, wrong dosage, bad methods, administering the drug at the wrong time, wrong preparation, and wrong prescription [11]. Also, medication errors are classified into three sets based on the drug application cycle as follows: errors in the drug prescription stage, errors in the distribution stage, and errors in the drug management stage [12].

The lack of the pharmacological information, imprecise drug calculations, lack of observing the predetermined drug and pharmacological contracts, illegibility of physician prescriptions, the existence of drug names' similarities, drugs' improper packaging styles, drugs' packages and containers similarities are among the common medication errors, and reasons such as shortage of time, the lack or nonexistence of instruments and tools, and insufficient number of personnel indirectly affect medication errors [13]. These errors are nowadays regarded as a main concern in health care-providing services, and they are currently considered as an index for determining patients' safety margin in the hospitals [14]. There exists no precise and compiled statistics of the amount of such medication errors in Iran, but the ministry of health and treatment and medical education has announced that billions of dollars are spent on taking care of and keeping the patients in hospitals due to medication error reasons every year, and the increase in the number of complaints and lawsuits by the people against physicians and nurses is indicative of such a claim [15]. The nurses are the frontline service providers in hospitals who play a particular role in providing service to the patients, drug management and interaction with the clinical staff. Therefore, the survey and determination of the reasons behind medication errors from their perspective can be influential on the identification of errors and application of appropriate strategies in preventing such errors by teaching past or prior experiences [16,17]. Therefore, the present study's objective is the survey of the medication error reasons from the perspective of nurses. 
Citation: Pournamdar Z, Zare S (2016) Survey of Medication Error Factors from Nurses' Perspective. Biol Med (Aligarh) 8: 310. doi: 10.4172/0974-8369.1000310

Page 2 of 4

\section{Methods}

The present study is a descriptive research performed on 119 nurses, all of whom were selected randomly in 2016. To collect the required information, a two-part questionnaire was applied which consisted of two parts: the first part pertained to the demographic characteristics (age, gender, work history, and having passed a course on ethics), and the second part was related to the evaluation of medication errors. The medication errors questionnaire contained twenty-one items, and it assessed medication errors in three areas including: nurserelated factors (seven items), department-related factors (six items) and nursing management factors (eight items). The items were scored based on Likert's five-point scale from "completely agree" (score 5) to "completely disagree" (score 1). In the next stage, the scores of each of the questions and areas were calculated. The content validity of the questionnaire was confirmed in a study performed by Hussein Zadeh et al. [18], and the questionnaire's reliability was obtained as 0.91 based on Cronbach's alpha method.

To collect data, after acquiring a confirmation letter for the research plan from the research vice chancellorship of Zahedan University of Medical Sciences and after obtaining a letter of recommendation and making the necessary coordination with the hospital, the researcher referred to the hospital and firstly explained the study objectives, and then the questionnaires were distributed in adequate number among the respondents. To inform the participants of their cooperation with the research, at the beginning of the questionnaire there was inserted a text which read "your cooperation with the present research means that you consciously agree to participate in the present study. Also, the information herein is confidential and the respondents are not exposed to any risk by any means." After the questionnaires were gathered and reviewed by the researcher, incomplete questionnaires were returned to the respondents to be completed. In the end, after the questionnaires were collected, the data were analyzed by SPSS 19 software and by the use of descriptive statistics.

\section{Results}

The individual's average age was $28.86 \pm 6.45 ; 101$ individuals (84.9\%) were women, and 87 individuals $(73.1 \%)$ had participated in courses on ethics. Sixty-four individuals $(53.8 \%)$ had a work history of $1-5$ years; 38 individuals (31.9\%), 5-10 years; 11 (9.2\%) individuals, $10-15$ years; and 6 individuals (5\%), above 15 years. The highest mean score belonged to the dimension of departmental factors. Also, the highest mean score pertained to the items "the low number of the nurses in relation to the number of patients" and "high volume of work," and the lowest mean score was related to the item "despondency and disinterest in nursing profession."

Frequency, mean, and standard deviation regarding medication error reasons-questionnaire items from the perspective of nurses have been given in Table 1 .

\section{Discussion}

In the present study, the highest score was related to departmentrelated factors, and the highest mean scores pertained to the items "the

\begin{tabular}{|c|c|c|c|c|c|c|c|}
\hline & $\begin{array}{l}\text { Your perspective regarding mediation } \\
\text { error-reasons questionnaire }\end{array}$ & $\begin{array}{l}\text { Completely } \\
\text { disagree (\%) }\end{array}$ & Disagree (\%) & No idea (\%) & Agree (\%) & $\begin{array}{c}\text { Completely } \\
\text { agree (\%) }\end{array}$ & $\begin{array}{l}\text { *Mean and } \\
\text { standard } \\
\text { deviation }\end{array}$ \\
\hline \multirow{7}{*}{ Nurse-related factors } & $\begin{array}{l}\text { Being despondent and disinterested in nursing } \\
\text { profession }\end{array}$ & 28.6 & 21.8 & 21 & 22.7 & 5.9 & $2.55 \pm 1.28^{*}$ \\
\hline & Nurses being unfamiliar with the drugs & 20.2 & 27.7 & 16.8 & 28.6 & 6.7 & $2.74 \pm 1.25^{*}$ \\
\hline & Nurses' economic problems & 16 & 26.1 & 18.5 & 26.9 & 12.6 & $2.94 \pm 1.29^{*}$ \\
\hline & Nurses' family problems & 21.8 & 17.6 & 17.6 & 34.5 & 8.4 & $2.90 \pm 1.31^{*}$ \\
\hline & Nurses' psychological and mental problems & 16.8 & 15.1 & 14.3 & 40.3 & 13.4 & $3.18 \pm 1.32^{*}$ \\
\hline & Not having enough time & 13.4 & 13.4 & 10.1 & 41.2 & 21.8 & $3.45 \pm 1.33^{*}$ \\
\hline & Tiredness resulting from overworking & 7.6 & 5.9 & 11.8 & 42.9 & 31.9 & $3.86 \pm 1.15^{*}$ \\
\hline \multicolumn{8}{|c|}{ Nurse-related factors' total mean score: $3.08 \pm 0.82^{*}$} \\
\hline \multirow{6}{*}{$\begin{array}{l}\text { Department-related } \\
\text { factors }\end{array}$} & Department environment noise & 8.4 & 14.3 & 18.5 & 41.2 & 17.6 & $3.45 \pm 1.18^{*}$ \\
\hline & Drugs chamber office space (light, physical space) & 16 & 15.1 & 19.3 & 35.3 & 14.3 & $3.17 \pm 1.30^{*}$ \\
\hline & Department type & 15.1 & 16.8 & 18.5 & 32.8 & 16.8 & $3.19 \pm 1.32^{*}$ \\
\hline & High volume of work & 5.9 & 5.9 & 9.2 & 49.6 & 29.4 & $3.91 \pm 1.07^{*}$ \\
\hline & The way drugs are arranged on the shelves & 10.1 & 15.1 & 26.1 & 37 & 11.8 & $3.25 \pm 1.15^{*}$ \\
\hline & Department medication and drug protocols & 15.1 & 16 & 27.7 & 32.8 & 8.4 & $3.03 \pm 1.20^{*}$ \\
\hline \multicolumn{8}{|c|}{ Department-related factors' total mean score: $\mathbf{3 . 3 3} \pm \mathbf{0 . 8 4 ^ { * }}$} \\
\hline \multirow{8}{*}{$\begin{array}{c}\text { Factors related to nursing } \\
\text { management }\end{array}$} & $\begin{array}{l}\text { The insufficient number of nurses in relation } \\
\text { to the patients }\end{array}$ & 7.6 & 3.4 & 15.1 & 38.7 & 35.3 & $3.91 \pm 1.15^{*}$ \\
\hline & Department style of supervision and control & 10.1 & 19.3 & 30.3 & 29.4 & 10.9 & $3.12 \pm 1.15^{*}$ \\
\hline & Drug prescription method & 14.3 & 21.8 & 21.8 & 33.6 & 8.4 & $3.00 \pm 1.21^{*}$ \\
\hline & Physicians' illegible handwriting in patients' files & 7.6 & 13.4 & 15.1 & 42.9 & 21 & $3.56 \pm 1.18^{*}$ \\
\hline & Kardex illegibility & 10.9 & 13.4 & 20.2 & 41.2 & 14.3 & $3.34 \pm 1.20^{*}$ \\
\hline & The errors occurring mostly during morning shifts & 16 & 27.7 & 31.1 & 21 & 4.2 & $2.70 \pm 1.10^{*}$ \\
\hline & The errors occurring mostly during evening shifts & 12.6 & 24.4 & 31.9 & 23.5 & 7.6 & $2.89 \pm 1.13^{*}$ \\
\hline & The errors occurring mostly during night shifts & 16.8 & 16.8 & 26.9 & 26.9 & 12.6 & $3.02 \pm 1.27^{*}$ \\
\hline
\end{tabular}

Table 1: Frequency, mean, and standard deviation regarding the medication error reasons-questionnaire items from the perspective of nurses 
low number of the nurses in respect to the patients in departments" and the "high volume of work." Environmental distracters such as the department's environment being nonstandard, not having independent rooms for drugs and medication preparation, and the crowd and noise cause nurses to lose part of their concentration on important occasions, and consequently medication errors occur.

Therefore, improving the work-environment conditions can reduce the number of occurrences of medication errors before they can cause injuries to patients. The use of a simple and less costly instrument, such as a drug prescription checklist, causes a decrease in the environmental effects on medication errors' occurrence [19]. In a study performed by Karren et al., $67 \%$ of nurses working in the children's department reported that they have committed medication errors at least once [20]. Medication errors may happen in each of the medication administration processes. The rate of such medication errors is higher in the first visit than the next visit [21]. Tang et al. asserted that the shortage in the number of the staff causes a decrease in the work quality and an increase in the number of medication errors [22].

One important reason behind medication errors in nurses is the wrong medication calculations, and in a study, the results were indicative that one-sixth of medication errors by nurses are due to wrong and faulty drug computations [23]. It seems that calculation errors are resulting from the weakness in the computational skills of nurses; thus it is suggested that there should be established a unit with the title Drug Computation for enhancing and exercising nurses' mathematical skills, and nurses should be fully informed of what they are expected to do in workshops, or relearning and re-exercising programs should be held in treatment centers, and the necessary information required for the routine drug computations should be provided in written form for each of the department personnel.

Also, it is recommended that the pharmacological companies act with due care in selecting drug names and packaging particularly dangerous drugs such as potassium chloride, magnesium sulfate, the medication errors of which causes severe injuries and even death to patients. The electronic method of writing prescriptions can be applied as a strong and effective tool in reducing the number of the errors related to drugs and nursing-care services and regimes [19]. In the study performed by Taheri et al., the study findings showed that the longer the shift's duration the greater the number of medication errors [24]. Working in night shifts is against the human being's intrinsic features, and it disturbs day-night rhythms and causes disorders in nurses such as sleeping disorders, tiredness, inexactness and lack of concentration, and irritability [25].

Some of the studies have shown that there is no significant difference between the error rates in the individuals who have passed the relearning course on drug administration and the nurses who have not passed this course [25]. Therefore, it is suggested here that relearning workshops should be held for personnel to reduce the rate of medication errors.

\section{Conclusion}

Enhancing awareness regarding the types and reasons behind medication errors and the reporting method is what should really be implemented in treatment and health centers and especially in training hospitals associated with Zahedan University of Medical Sciences in nursing staff group. Intensive work volume, stress and high work tension, and the high sensitivity of the nursing occupation are among factors which cause early and extreme tiredness in nurses and eventually lead to the occurrence of work-related errors and mistakes and sometimes with a great frequency; therefore, there is a need for preparatory measures for adjusting the nurses' working hours in high-intensity work environments, establishing constraints regarding overtime shifts' adjustments.

\section{Acknowledgments}

This study was the result of a student research project approved at Zahedan University of Medical Sciences. Hereby, we express our deep gratitude to those people who participated and collaborated in this study and to the research authorities of Zahedan University of Medical Sciences who helped us in the process of data collection and supported us financially.

\section{References}

1. Jahantigh M, Zare S, Shahrakipour M (2016) The survey of the relationship between ethical climate and ethical behavior in nurses. Der Pharm Lett 8 : 189-193.

2. Miandoab NY, Shahrakipour M, Zare S (2016) The study of relationship between the ethical climate and job interestedness. Der Pharm Lett 8: 86-90

3. Gorgich EAC, Barfroshan S, Ghoreishi G, Yaghoobi M (2015) Investigating the causes of medication errors and strategies to prevention of them from nurses and nursing student viewpoint. Global J Health Sci 8: 220.

4. Young $\mathrm{H}$ (2008) Lack of pharmacological training causes overuse and misuse of drugs. Can Med Assoc J 178: 276.

5. Unver V, Tastan S, Akbayrak N (2012) Medication errors: perspectives of newly graduated and experienced nurses. Int J Nurs Pract 18: 317-324.

6. Nasab M (2009) Analyzing the knowledge and attitude of nurses regarding medication error and its prophylactic ways in educational and therapeutic hospitals of Khorramabad. Yafteh 10: 55-63.

7. Armitage G, Knapman H (2003) Adverse events in drug administration: a literature review. J Nurs Manage 11: 130-140.

8. Baghcheghi N (2010) The Comments of nursing educators about reasons and reduction strategies of medication errors in nursing students in Arak University of Medical Sciences, 2008. Arak Med Univ J 12: 1-8.

9. Jolaee S, Hajibabaee F, Peyravi H, Haghani H (2009) Nursing medication errors and its relationship with work condition in Iran University of Medical Sciences. Iran J Med Ethics Hist Med 3: 65-76.

10. Webster CS, Anderson DJ (2002) A practical guide to the implementation of an effective incident reporting scheme to reduce medication error on the hospital ward. Int J Nurs Pract 8: 176-183.

11. Aronson JK (2009) Medication errors: definitions and classification. Br J Clin Pharmacol 67: 599-604.

12. Salavati S, Hatamvand F, Tabesh H (2012) Nurses' perspectives on causes of medication errors and non-reporting at ED. Iran J Nurs 25: 72-83.

13. Carlton G, Blegen MA (2006) Medication-related errors: a literature review of incidence and antecedents. Annu Rev Nurs Res 24: 19-38.

14. Mohammad Nejad S, Hojjati H, Ehsani R (2008) The amount and type of medication errors in nursing students in four teaching hospitals of Tehran. $\mathrm{J}$ Med Ethics Hist Med 88.

15. Balas MC, Scott LD, Rogers AE (2004) The prevalence and nature of errors and near errors reported by hospital staff nurses. Appl Nurs Res 17: 224-230.

16. Ligi I, Arnaud F, Jouve E, Tardieu S, Sambuc R, et al. (2008) latrogenic events in admitted neonates: a prospective cohort study. The Lancet 371 : 404-410.

17. Barker KN, Flynn EA, Pepper GA, Bates DW, Mikeal RL (2002) Medication errors observed in 36 health care facilities. Arch Intern Med 162: 1897-1903. 
Citation: Pournamdar Z, Zare S (2016) Survey of Medication Error Factors from Nurses' Perspective. Biol Med (Aligarh) 8: 310. doi: 10.4172/0974-8369.1000310

Page 4 of 4

18. Hosseinzadeh M, Ezate Aghajari P, Mahdavi N (2012) Reasons of nurses' medication errors and persepectives of nurses on barriers of error reporting. Hayat 18: 66-75.

19. Pape TM, Guerra DM, Muzquiz M, Bryant JB, Ingram M, et al. (2005) Innovative approaches to reducing nurses' distractions during medication administration. J Contin Educ Nurs 36: 108-116.

20. Stratton KM, Blegen MA, Pepper G, Vaughn T (2004) Reporting of medication errors by pediatric nurses. J Pediatr Nurs 19: 385-392.

21. Hughes RG, Ortiz E (2005) Medication errors: why they happen, and how they can be prevented. J Infusion Nurs 28: 14-24.
22. Tang F, Sheu S, Yu S, Wei I, Chen C (2007) Nurses relate the contributing factors involved in medication errors. J Clin Nurs 16: 447-457.

23. Rainboth L, DeMasi C (2006) Nursing students' mathematic calculation skills Nurse Educ Pract 6: 347-353.

24. Taheri E, Norian M, Rasoli M, Kavoosi A (2013) The study of type and amount of medication errors in neonatal intensive care units and neonatal units. J Crit Care Nurs 6: 21-28.

25. Yousefi MS, Abed Saeedi Z, Maleki M, Sarbakhsh P (2015) Frequency and causes of medication errors of nurses in. J Shahid Beheshti School Nurs Midwifery 24: 8454. 